\title{
Entrepreneurial treatment activism for undone science: mannitol and Parkinson's disease
}

\author{
Shlomo Guzmen-Carmeli ${ }^{1}$ (D) David A. Rier $^{1}$ (D)
}

Accepted: 22 September 2021 / Published online: 23 October 2021

(C) The Author(s), under exclusive licence to Springer Nature Limited 2021

\begin{abstract}
This paper describes CliniCrowd, a patient-designed, entrepreneurial, crowd-sourced citizen-science approach to evaluating mannitol-essentially, an orphan drug - as a Parkinson's disease treatment. As such, CliniCrowd addresses 'undone science', and our paper contributes to the sociological literature thereon. Based on 38 qualitative interviews, fieldwork, and content analyses (2017-2020), we trace CliniCrowd's background and rationale. We: discuss undone science and its wider contexts; present earlier iterations of citizen-science and treatment activism; examine CliniCrowd's application of crowd-sourced citizen-science to address undone science around 'orphan drug' treatment for Parkinson's disease; explore how CliniCrowd has evolved, and re-framed its work, since its founding; ponder its future; and consider whether their approach can guide future citizen-science treatment research. Our paper contributes to the existing literature in four ways. First, we focus on medical treatment issues, an under-studied area of undone science. Second, we highlight orphan drugs as both major source of, and fruitful area for research on, undone science. Third, we describe CliniCrowd's pragmatic, entrepreneurialrather than the more common activist-citizen-science approach to addressing undone treatment science. Finally, from our data on CliniCrowd we distil a preliminary model for future treatment activism around undone science.
\end{abstract}

Keywords Undone science · Crowd-sourcing · Treatment activism · Parkinson's disease $\cdot$ Expertise $\cdot$ Entrepreneurial activism $\cdot$ Citizen-science

Shlomo Guzmen-Carmeli shlomoguzmen@gmail.com

David A. Rier

rierda@gmail.com

1 Department of Sociology \& Anthropology, Bar-Ilan University, 5290002 Ramat-Gan, Israel 


\section{Introduction}

This paper describes an atypical, pragmatic, 'entrepreneurial' approach to addressing 'undone science' via treatment activism.

\section{Undone science}

Scientific questions do not all have equal chances of being explored. Undone science refers to "areas of research identified by social movements and other civil society organizations as having potentially broad social benefit that are left unfunded, incomplete, or generally ignored" (Frickel et al. 2010, p. 445). It usually describes research un-performed for financial, theoretical, disciplinary, career, ideological, political, and/or other reasons (Hess 1998, 2009, 2015, 2016; Woodhouse et al. 2002; Frickel et al. 2010). This condition frequently results from the "systematic tendency for knowledge production to rest on the cultural assumptions and material interests of privileged groups" (Frickel et al. 2010, p. 446); see also Hess (2016, p. 41).

It is one sub-set of the wider, classic question of scientists' topic-selection (e.g., Hagstrom 1965; Zuckerman 1978; Gieryn 1978; Ziman 1987). It is also a sub-set of the contemporary social study of ignorance and its production (Frickel 2014; Gross and McGoey 2015). To an extent, these questions also parallel the broader area exploring which issues ascend the public agenda to be designated as important social problems, and why (Gusfield 1981; Hilgartner and Bosk 1988).

Hess (2016) has produced a deep, multi-dimensional inquiry into the phenomenon of undone science. He discussed this in the wider context of "mobilized publics," "counterpublics" (pp. 7,16) mobilized in challenge to "incumbent", "official" (p. 17) actors, and seeking to influence institutions to achieve some form of societal change. His particular focus was on "industrial transition movements", counterpublics mobilized to: "reform society by changing technologies, products, and industrial processes. They also attempt to change the social relations of industry to improve basic access to material goods or to alter the social organization of industrial production" (pp. 20-21).

In this context, Hess wrote, undone science referred to "the systematic absence of research identified by counterpublics when they seek to document potential risks and uncertainties of technologies and industrial processes, and they find that the desired research has not been done or has been significantly underfunded" (p. 7).

Hess (2016) created a typology of industrial transition movements, classified by goals, "repertoires of action", definitions of undone science, "routinization of patterns", and also by whether the given movement focused on either technologies, themselves (whether improving, reforming, promoting, or even terminating, a given technology) or on altering processes, the "organizational and distributional dimensions of industrial systems" (p. 42). He termed his ideal-types of movements: alternative industrial; industrial opposition; industrial restructuring; 
and industrial access. Movements vary across categories in their composition, motivation, the levels of 'epistemic conflict' their work engenders, and other factors.

The present study is very far from a formal test of Hess's framework of undone science. However, in this paper, we draw often on his insights to elucidate the work of 'CliniCrowd', whose entrepreneurial approach to crowd-sourced treatment activism we describe in detail. As we hope to demonstrate, our paper extends the existing literature in four ways. First, we widen the focus of undone science research by dealing with medical treatment issues, insufficiently explored heretofore. Second, we highlight orphan drugs as both significant source of, and fruitful area for research on, undone science. Third, we expand the broader citizen-science literature by describing CliniCrowd's entrepreneurial (rather than the more common activist) approach to treatment activism for addressing undone science. Finally, from our data we distil a basic, preliminary model for future efforts to address undone science.

The problem of undone science long predates the term. Frickel et al. (2010) identified roots of undone science theory in the work of Marx, as well as in that of feminist and of multi-cultural science studies scholars. Much of the activism around toxic-exposed communities, since the 1970s (Brown and Mikkelsen 1990), and HIV/AIDS, since the 1980s (Epstein 1991, 1996; Indyk and Rier 1993), for example, involved pressure to perform needed-but-undone research. Often, citizen-scientists hoped their preliminary grassroots efforts would attract larger, more authoritative studies by formally-trained and -certified (i.e., 'credentialed') scientific experts (Arancibia and Motta 2019; Brown and Mikkelsen 1990).

The formal concept of undone science arose largely from within environmental concerns, which remain a primary focus. Recent examples include studies of: crowdsourcing for environmental activism (Ottinger 2017); Brazilian nuclear energy discourses following Japan's Fukushima disaster (Goldstein 2017); failure of French officials to produce studies of industrial pollution's health effects relevant to affected communities (Allen et al. 2017); and mining's environmental impact on an indigenous Alaskan population (Panikkar 2020). Yet scholars have also applied the undone science concept to other issues, including: production of community-relevant transportation research (Lowe 2020); trans-sexual health issues in Argentina (Hanssmann 2020); and research on cancer amongst Tasmanian devils (Warren 2015).

Pertinent to the present study, Cleary (2012) has invoked undone science to explain the lack of clinical research for one inexpensive medical treatment because another, costlier drug was more lucrative. Hess (2016, p. 28), himself, has made this very point:

cancer researchers prefer to develop new therapies that are aligned with the standard of patented, testable drugs supported by the pharmaceutical industry, regulated by the government, and routinized in oncology practices. Those who challenge the industrial regime by advocating the less lucrative but potentially also less expensive and less toxic alternatives of high-dose nutritional supplements and changes in diet and lifestyle tend to be in a subordinate position, and they may even experience intellectual suppression.... 
A terminological aside. The traditional lay/expert divide is increasingly recognized to be deeply problematic (Eyal 2019). The definition and locations of expertise are fluid; they shift with the specific question, and can include local 'experts' lacking formal, specialized scientific training (Rier and Indyk 2006a, p. 19). We therefore qualify such traditional terms as 'expert' and 'scientist' with 'formallycredentialed'. 'Citizen-scientist' (Swan 2012; Kempner and Bailey 2019), a term encompassing multiple ways in which those without formal scientific training or relevant professional certification engage in science, replaces 'lay'.

Having introduced the concept of undone science, we next: review the history of treatment activism; present our research methods; describe CliniCrowd and how its tactics have evolved over time-and ponder its future; and consider whether their pragmatic, entrepreneurial approach can guide future citizen-led efforts to get undone science done.

\section{Treatment activism: antecedents and parallels}

Today's digital platforms are re-defining boundaries and connections between patients, their bodies, physicians, and biomedical knowledge (Petersen et al. 2019; Petracci et al. 2017; Conrad et al. 2016). One strand of this revolution manifests as patient activism. Examples include: self-experimentation and crowd-sourcing (Kempner and Bailey 2019; Wicks 2018; McGowan et al. 2017); evidence-based activism (Akrich et al. 2014; Rabeharisoa et al. 2014b); self-monitoring (Callon and Rabeharisoa 2003; Lupton 2013, 2017; Piras and Miele 2017); treatment-access advocacy (Petersen et al. 2015); and shifts from resistance to cooperation (Petersen et al. 2019). Each of these appears in the work of CliniCrowd, the Israeli patient-led, crowd-sourced, treatment-research enterprise at the heart of this paper.

Fully to appreciate the present case, we require some historical context. While today widely accepted that citizen-scientists, rather than only physicians and formally-credentialed scientists, can conduct medical research, Parsons' (1951) classic model of the patient's sick role assumed that all agency resided with the physician, who acted upon passive patients. Indeed, this reasonably reflected the mid-century doctor-patient role. By 1964, however, journalist Norman Cousins (1976) was already experimenting with applying, to his own treatment, his own holistic insights into the cause of his diseases. By 1970, in a confluence of feminism, consumerism, and self-help, the Boston Women's Health Collective (1970), united in their disillusionment with how medicine treated female patients (Norsigian et al. 1999), published Women and their Bodies: A Course, which soon grew into the oft-updated and -translated Our Bodies, Ourselves. During the 1970s and 1980s, largely workingclass residents of certain U.S. communities affected by toxic waste, after meeting official indifference, united to conduct some form of research with which to attract attention to their situation. Sometimes, they received support from credentialed scientists, ultimately forming citizen-scientist alliances for, not only data-collection, but also protracted struggles to beget larger studies, apply political pressure, and initiate (and sustain) lawsuits seeking change and redress (e.g., Cable and Cable 1995; Brown and Mikkelsen 1990; Brown 1992). 
However, it was the HIV/AIDS epidemic in the 1980s that catalysed the largescale entry of patients into, not only consumption and dissemination of medical knowledge, but also its production and assessment (Epstein 1991, 1996; Harrington 1997; Indyk and Rier 1993). Motivated by their conviction that the biomedical establishment were largely uninterested in saving them, AIDS activists began attending medical conferences (then, virtually unheard-of for patients), reading medical journals, disseminating their interpretation of their reading, discussing (and trying to obtain) alternative treatments, and mounting a cogent critique of mainstream AIDS research (Merigan 1990; Indyk and Rier 1993). Most relevant to our discussion, in 1987 Community Research Initiative, a partnership of community-based physicians and patients, began a grassroots clinical trial of aerosolized pentamidine as a treatment for pneumocystis pneumonia, then the leading threat to AIDS patients. The trial yielded important clinical data (Arno and Feiden 1992), swiftly influenced clinical practice, and was even used by the U.S. Food and Drug Administration (FDA) in the approval process (Cimons 1989; Indyk and Rier 1993). Activists also formed groups to identify and obtain (sometimes, via smuggling) potential treatments unavailable in the U.S. They criticized pharmaceutical companies for their high prices, and their failure to study a wider range of compounds. They particularly attacked the FDA's reliance on very slow, expensive randomised clinical trials (the traditional 'gold standard'), rather than a speedier drug-approval process that could more efficiently get potentially life-saving 'drugs into bodies' (James 1989; Indyk and Rier 1993; Epstein 1996; Harrington 1997).

By the mid-1990s, online support groups enabled those living with many conditions to reach beyond their physicians, via crowd-sourcing (Wazny 2018), for advice about diagnosis, treatment, and daily management (Conrad et al. 2016). By 2004, PatientsLikeMe (PLM) had been launched by two brothers and one friend of an amyotrophic lateral sclerosis (ALS) patient. It opened in 2006 as an online platform, allowing ALS patients to pool their uploaded, de-identified clinical data, to help assess their own progress, trade tips and support, and contribute more generally to emerging clinical knowledge about the disease. Eventually, PLM began using the database to conduct research (Agency for Healthcare Research and Quality 2017). By 2008, they had published their crowd-sourced study examining whether (as a small study, noticed in the media by one PLM member, had claimed) lithium relieved ALS symptoms (Wicks et al. 2008). PLM's work, later confirmed, led to that treatment's rejection (Kempner and Bailey 2019, p. 2). By February, 2021, their website (https://www.patientslikeme.com/about) claimed patient communities for over 2,900 conditions, with 830,000-plus patient-participants. They are currently a for-profit company, bought in 2019 by a large managed-care corporation. They sell aggregated, de-identified data to academic and corporate customers such as pharmaceutical and medical-device companies (PatientsLikeMe 2020). Today's crowdsourcing, self-experimenting citizen-scientists thus build on a diverse tradition of patient treatment activism.

For, the pioneering work of AIDS activists three decades ago, who first began attending scientific conferences and were prepared to challenge credentialed biomedical experts on the nature and direction of clinical research, helped usher in a world in which: 
$[\mathrm{m}]$ ost scientific conferences in the US are now attended by a scattering of 'amateurs', and for the professional their level of expertise is astounding, usually exceeding the professional (i.e. paid) scientist in breadth and depth. Why? Because they care about the subject directly....The amateur cares nothing for papers or grants - she wants to know. Most have educated themselves over the net. (Bain 2008, p. 715)

Against this rich backdrop, our paper explores several research questions. What conditions birthed CliniCrowd as a tool to do undone science by testing mannitol for Parkinson's? How has CliniCrowd functioned? Has this changed over time? What does CliniCrowd's approach offer future citizen-science treatment activism around undone science? This investigation offers insights for several areas, particularly around our own foci of medical sociology and science and technology studies (STS), but also for social movements research.

Note that we do not directly address mannitol's clinical efficacy. Not only will this likely take some years to become clear, but our purpose is not to investigate-much less endorse-mannitol's value in managing Parkinson's. Rather, we explore an interesting form of citizen-science treatment activism from a sociological perspective.

\section{Methods}

Our interest in CliniCrowd arose from our broader fieldwork on Parkinson's disease. When we recognized interesting changes in this field (involving, as mentioned, innovative ways to test mannitol), we sought to isolate them (see Yin 2018, p. 45). After a broad assessment of the various treatments offered to Parkinson's patients, we identified the subject of our specific case study (CliniCrowd), and then conducted in-depth examination of how and why the project was established and how it operated. We thus used a case-study methodology that focused on a particular organization, its founders, decision-making process, organizational narrative, and its contexts, over a sustained period. These were present-time events, over which we, as researchers, had no influence or control (Yin 2018, p. 39). This approach enabled us to produce an in-depth, real-life understanding of the project's evolving modes of operation.

As mentioned, a basic question is whether CliniCrowd furnishes a model for replication. This question shifts the case study from descriptive to explanatory, one facilitating suggestions for generalizations, or a possible model carefully derived from the particular case (Ragin and Becker 1992; Yin 2018). Precisely by focusing on a given company over time, we could follow a particular process that took place in the company, as well as extract a model for future activism (Ragin and Becker 1992; Yin 2018, pp. 63-64, 231-232, 326). 


\section{Interviews and sampling}

We conducted fieldwork 2017-2020. Its core were 31 audio-recorded, semi-structured, face-to-face interviews, with: 20 patients, five CliniCrowd personnel, three scientists studying Parkinson's, and three Parkinson's physicians. To clarify questions arising during data analysis, we supplemented these with four face-to-face follow-up interviews, plus three telephone follow-up interviews, with key CliniCrowd personnel. Thus, we conducted a total of 38 interviews (with 31 discrete informants); 35 were face-to-face.

During recruitment, invitations for patients to participate in our study were posted on forums and WhatsApp groups related to the CliniCrowd platform. We employed snowball sampling, focusing on those active on the CliniCrowd platform, and those taking mannitol. Patients were eligible if they: had been diagnosed with Parkinson's disease; were aged between 25 and 80 years; and could provide informed consent. We excluded patients for severe psychiatric or additional neurological disorders, or dementia. Interviews were transcribed; the first author translated interview selections from the Hebrew. We employed purposive sampling to identify non-patient respondents (i.e., CliniCrowd personnel, physicians, and scientists).

Topics addressed during interviews varied across different categories of respondents. Patients were queried about their illness, how they learned of mannitol, why they used it, and how their physicians responded to that decision. We asked CliniCrowd staff about topics such as: their role in the enterprise; their personal histories; and CliniCrowd's process of decision-making, over time. Topics discussed with physicians included: how they had heard of mannitol's possible value for Parkinson's; whether they had read research on it; and whether (and if so, when) they had recommended mannitol to patients. We asked scientists to describe their relevant research, and how they became involved in the clinical trials. The interview with the founder/chair was longer and deeper, covering his experiences with Parkinson's, his establishment of CliniCrowd, but also his broader life story.

Our research case is unique in terms of its particular contexts related to the relatively militarized culture and discourse of the Israeli setting. As we suggest below, however, this case bears implications for activities far beyond this local context, ones in which entrepreneurially oriented activists can succeed by identifying and/or creating new spaces through which to complement rather than resist existing frameworks.

\section{Consent and confidentiality}

Interviewees were promised confidentiality (but see below), and verbally consented to being interviewed.

Regarding our respondents' identities, we replaced all patients' (with one special exception, explained below) actual names with pseudonyms. However, regarding the balance of respondents, in this paper we have identified certain key informants (one of whom was also a patient in the mannitol trial) by their actual names. We now explain why. 
That CliniCrowd is quite a distinctive project-particularly in comparatively small Israel-undermined our attempts to conceal its identity. Management consented to our naming them in our paper. Moreover, there were several informants (including senior researchers and project founders) whose anonymity, we believed, could not be preserved, given the media coverage and publicity they have generated. For example, as of June 13, 2021, Googling "mannitol" and "Israel" instantly yielded the name, in the first and second (non-advertisement) items returned, of CliniCrowd's founder-chair-who is also, himself, participating as a patient in the mannitol trial. These individuals consented for their real names to be used. Thus, when non-patient informants are quoted by name, these are their real names, unless labelled as pseudonyms. Similar methodological difficulties led anthropologist Bilu (2010) to describe major institutions and persons in his work by name.

We reiterate that the confidentiality of all the patients (except for that founderchair) whom we met and interviewed for this study has been preserved throughout fieldwork and in this paper.

\section{Supplemental methodologies and analyses}

Fieldwork also included observations made at medical conferences, and during patients' special exercise sessions. Content analyses examined: the company's website; the forum dedicated to patients taking part in the project; and print and electronic media coverage. This fieldwork, conducted simultaneously in several areas, helped us understand several significant aspects of CliniCrowd and its work.

We analysed the materials collected via the case study approach (Yin 2018, pp. 213-223). During initial data analysis, we focused on several questions: how has CliniCrowd's narrative changed over time? How were various actors exposed to information about mannitol, the patients' initiative, meetings with other patients, and online publications? How did physicians view information about the use of mannitol and CliniCrowd's activity? And finally, have physicians' attitudes towards mannitol changed?

Answering these questions helped generate a timeline through which to spot and understand changes occurring in the field. Tracking our subjects' changing use of terminology and rhetoric in the field revealed certain key shifts, described below, in how CliniCrowd framed their work. Added to these tactics were the content analysis methods that characterize qualitative research.

We also explored these fieldwork data both through the narrative method of analysis (Lieblich et al. 1998; Andrews et al. 2013), to examine the circumstances behind CliniCrowd's establishment, and thematic analysis (Miles and Huberman 1994; Braun and Clarke 2006), which offered an initial interpretive reading and reduction of the material, its conceptualization, and thematic processing.

Through the above-described research process, in which we worked the data "from the ground up" (Yin 2018, p. 217), we distilled a model (presented in the Conclusion), from our case analysis, for further entrepreneurial activism to address undone science. 
In the next section, we offer our findings. In the interview quotations presented, ellipses are added.

\section{Results: an orphan drug start-up story}

Meet Dan Vesely, retired Israeli general and high-tech start-up entrepreneur. Here, he describes his response to his own 2013 Parkinson's disease diagnosis:

This is how I was trained in the service: if there's a problem, deal with it. No crying over spilled milk or grieving about my misfortune, about what I 'won' [said cynically]. Come on, what do we do next? We think of solutions. [interview, January 24, 2018]

This paper examines the solution that Vesely and his associates developed: CliniCrowd, a digital 'global community' adopting an alternative approach to clinical research. The initiative was established after the discovery that a substance called mannitol might improve the condition of Parkinson's patients. This discovery was, essentially, being ignored for lack of significant profit potential. Below, we describe how CliniCrowd adopted mannitol as a treatment for Parkinson's, and how their efforts evolved over time, employing different tactics to meet their shifting challenges as they sought to turn undone to done science.

Specifically, these key phases have been: (1) identification of and frustration over undone science; (2) the decision to circumvent lengthy, inefficient modes of operation; (3) framing as resistance; and 4) exploitation of ways to avoid direct resistance to established actors, in favour of re-framing themselves as complementing, rather than resisting, the status quo.

\section{Phases and tactics: 1. Frustration over undone science}

Mannitol is a powdery, natural substance used in the food industry as a sweetener. Hospitals employ intravenous mannitol to reduce intracranial pressure. Our study examined mannitol's oral use.

Between 2012 and 2014, several pre-clinical studies conducted by a team of researchers at Tel-Aviv University, headed by Professors Dan Segal and Ehud Gazit, indicated therapeutic potential of mannitol against clumps of alpha-synuclein protein, a known sign of Parkinson's disease. The researchers were seeking a substance that breaks down these protein clumps in vitro; they discovered that mannitol does this very effectively. They next examined mannitol's impact on fruit flies (Drosophila) into which the human Parkinson's gene had been transplanted. This transplant severely impaired these flies' motor function, disrupting their ability to climb the walls of a test tube. The researchers found that mannitol significantly improved the sick flies' motor function and climbing ability. Post-mortem analysis of mannitoltreated flies' brains showed that the amount of alpha-synuclein protein had decreased $70 \%$. Next, they studied mice in whose brains the gene was implanted to produce the protein that causes brain disease in humans. Here, too, mannitol injection markedly 
decreased formation of Parkinson's disease-related structures. After a few weeks, the mice receiving mannitol showed decreased Parkinson's symptoms, and began to run and climb in their cages. Following these encouraging results, the obvious next stage was human experimentation...but here, things got complicated.

The researchers stated that these studies did not progress to the clinical trial stage. A natural substance found in many plants and algae, mannitol and its products cannot be patented. Moreover, given the ageing population, with concomitant rising rates of Parkinson's, the global market value of Parkinson's drugs (the overwhelming majority of which are symptomatic drugs with significant side effects), is enormous. Already worth billions annually, it is projected to experience a compound annual growth rate of about 11.3\% from 2020 to 2027 (Accumen Research and Forecasting 2021). All this has rendered mannitol unattractive to pharmaceutical companies (and also to government and academic researchers, according to our informants), who have declined to test its value for treating Parkinson's.

This is how one researcher involved in the study, Moshe [pseudonym], described his frustration:

It's not easy, knowing there is clear potential, yet the research has been shelved. The frustration is very great. It raises a lot of questions about the implications of scientific research. Whom does research serve: science, patients, or other [interests]? [interview Jan. 26, 2020]

Following several years pursuing funding to test mannitol on Parkinson's patients, the team published an article in a respected chemistry journal (ShaltielKaryo et al. 2013), and moved on to the next research project.

Abigail [pseudonym] is a veteran researcher who has led clinical trials at several international drug companies:

My research stopped, the money ran out, and I saw, to my regret, that projects are simply stalling and there are still questions. It's not that the project is inefficient; often, I've seen good projects that have been shelved because of financial considerations. As you go up the ranks it becomes more evident, and I found it myself....in an Israeli pharmaceutical company, and also deep within international companies with tens of thousands of workers. You realize that the patient's welfare in these places becomes secondary: the money, the investors come first.... I'm not against making money, it's okay to make money, as long as you protect the patient's welfare above all. [But] when the good of the patient is neglected due to financial considerations-I mean, we have a very good project, but we haven't yet patented it, and [the new project] is a better treatment, but we will not release it to the world until we patent it, and then we will renew the patent [of the old drug], even though we know we already have something better. And my conscience had a hard time accepting this behaviour. [interview June 12, 2018]

These cases led Abigail to leave the pharmaceutical industry. She began working with Vesely on what became CliniCrowd's project to explore natural substances with clinical potential. 
Based on earlier treatment activism, we observe that the orphan is often parent to innovation. Thus, the original AIDS activists were motivated partly by their conviction that AIDS was essentially an orphan disease since, they assumed, mainstream actors would care little about a disease striking mainly marginalized, stigmatized groups (Indyk and Rier 1993). Similarly, French activists for muscular dystrophy (MD), given its comparative rarity, recognized that MD's 'orphan' status confronted them with "being abandoned by the medical and scientific profession" (Callon and Rabeharisoa 2003, p. 197). In both cases, activists concluded that their fates lay in their own hands; orphan status thus helped stimulate significant patient-led innovations in the creation, diffusion, assessment, and application of new knowledge.

Treatments can also be orphans-with similar stimulus to innovation. We normally understand orphan drugs as those aimed at orphan diseases-those so rare that commercial manufacturers would expect little profit, hence do not produce them (Mikami 2017). Yet another type is one which, though useful for a common-enough disease, cannot be patented, hence is not commercially produced (Orphanet 2019).

This describes mannitol-although the real obstacle here is testing, not production. Other entities can produce and distribute mannitol reasonably simply and inexpensively. CliniCrowd's problem — and key role-lies upstream: getting mannitol properly tested, to demonstrate its efficacy in humans to physicians and patients. Without prospects of corporate profits, the lengthy, costly process of formal trials is nearly impossible. As such, the phenomenon of orphan drugs represents an overlooked type of undone science, posing both an important, painful obstacle in treating disease, and an area ripe for research.

\section{Phases and tactics: 2: circumvention-(A) If you can't go through the door, go through the window}

The fusion of a former commando's mentality with that of a technology entrepreneur prompted Vesely to deploy his own resources to address his condition. Dissatisfied with his treatment options, he asked acquaintances for help. A small group of entrepreneurs banded together with him to search the published Parkinson's research. They soon noticed the published—and forgotten-study about the possible effect of mannitol on Parkinson's patients. Vesely and some partners contacted Professor Dan Segal of Tel-Aviv University, who had co-headed the research team, and asked to meet:

It had not yet been tested on humans. So I made an appointment....Prof. Segal told us his story, described the experiment, and said it's all simply been shelved, there's no incentive for the pharmaceutical companies. We looked at each other and said, 'So we'll take it!' The professor said, 'Who exactly are you? You brash Israelis, who are you?' But it was clear to us that if you can't go through the door, you go through the window. [Vesely interview, Jan. 24, 2018]

The story of the study and the lack of economic feasibility for clinical trials affected the group, comprised of former members of elite military units and 
high-tech entrepreneurs, coalescing around Vesely. Seeking to apply to himself, as patient, an approach traditionally reserved for researchers (Weisse 2012), Vesely resolved to test mannitol first on himself. However, his partners dissuaded him. Instead, they agreed to test mannitol on some number of Parkinson's patients.

Lacking a pharmaceutical company willing to invest in clinical research, they sought to test mannitol by launching a "circumvention of the entire medical system." Indeed, when discussing CliniCrowd, they repeatedly used such terms as: "reconnaissance unit"; "commando operation"; and "quick-and-dirty". These terms portray the mind-set of those accustomed to thinking creatively and acting decisively, specifically outside of existing frameworks and expected patterns.

They adopted a model, marrying patient self-experimentation with crowd-sourcing techniques (Swan 2012), described by Kempner and Bailey (2019, p. 4) as, "collective self-experimentation". Inspired by similar crowd-sourcing ventures like PatientsLikeMe, the group created a website providing its own platform for Parkinson's patients who agree to take mannitol regularly for an extended period. Applying the 'crowd wisdom' familiar to them from other high-tech ventures, the company asked patients registering on the site to complete a detailed monthly survey about their health, Parkinson's symptoms, and how they took mannitol. They analysed these data, which constituted an initial and rapid research alternative to formal clinical research.

This alternative is not a true substitute for 'proper' clinical trials. The survey platform lacks a control group, and patient surveillance is carried out through the site voluntarily and independently, and not by a physician. Nevertheless, they are generating preliminary data with which to justify the need for more formal clinical research. CliniCrowd's founders initially considered marketing mannitol directly, but decided against this, to avoid conflicts with their research. In fact, although CliniCrowd's prospects of ever becoming profitable are relatively limited, they nevertheless chose to register it as a corporation, rather than as a non-profit organization. This reflected their primary motivation of 'getting the job done' as quickly and efficiently as possible, via entrepreneurial tactics, rather than adopting the identity and tactics of social activism. As co-founder and CEO Amir Sadeh explained:

We want to fill a slot that deals solely with the welfare of the patient, so we are not concerned with marketing mannitol or its commercial aspects. But the management of a non-profit organization moves very slowly, like an aircraft carrier. They are very slow and cumbersome, with reports right and left. Whereas, the behaviour we're used to is more like a missile boat. If there are profits, they will be directed towards further research, not to our gain. The idea remains the same, to do good for humanity. The question is: how to do it fastest and best? [interview, December 3, 2017]

As elsewhere, Israeli non-profits are strictly regulated. Therefore, despite realizing that their company had no great profit potential, the founders of the venture, all entrepreneurs who had already earned significant wealth from their own companies, registered it as a corporation. It has enabled them to function more nimbly and more in accord with how they operate their other concerns. It is also consonant with their primary identity as entrepreneurs, rather than activists. 
They established the corporation in August, 2016, and began recruiting patients with the help of patient forums and media exposure. They recruited trained personnel experienced in planning and conducting clinical trials to create the company's platform. It did not simulate a true clinical trial, but created a valuable database by recruiting patient volunteers on the Internet. According to our informants, by early 2021, 2,480 patients had registered on the platform dedicated to researching mannitol for Parkinson's. Of these, 1,364 (55\%) had filled out questionnaires, multiple times. The platform has enabled patients to record and track data related to their illness and (while maintaining anonymity) compare these data with those from other members of the community. It was also possible to share the stored data with the treating physician. As mentioned above, the platform's primary function has been to examine the effect of mannitol on Parkinson's patients, thereby making the patients active participants in the trial of a treatment that has not hitherto been tested on humans.

CliniCrowd's efforts at getting undone science done have involved several stages. Launching the crowd-sourced study was the main step. As Parkinson's patients on the platform began taking mannitol, and regularly completing questionnaires about their symptoms, an alternative body of research began to emerge. The primary value of this research was in the subsequent step of attracting credentialed scientists to conduct larger trials. CliniCrowd's initial data sparked public pressure, in turn leading to a formal clinical study, launched in 2018 at Hadassah Medical Center in Jerusalem. That study (https://clinicaltrials.gov/ct2/ show/NCT03823638), conducted with public funding, examines the effects of mannitol on Parkinson's disease. As of June, 2021, the study was continuing, but had slowed somewhat due to Coronavirus and its severe impact on the medical system. Additional studies, at universities and medical centres in the UK and the US, are expected to begin shortly. As far as we know at time of writing, these are limited studies.

Nonetheless, there has already been a significant turnaround regarding how scientists regard mannitol research. As Vesely, CliniCrowd's patient-founder, remarked:

It gives me great satisfaction that the studies we are currently talking about [the clinical research underway in Jerusalem and expected further studies] would not have taken place, nor would they have received funding or the attention of the medical establishment and the public, without the buzz and especially the clinical indications that CliniCrowd achieved in the wake of the surveys. [interview, July 7, 2019]

Researchers involved in planning the clinical trial have confirmed to us in interviews that, without the pressure applied by the public, it is unlikely that a trial would have been initiated. Vesely's use of the term, 'buzz' referred to public and media activity that placed the issue on the public agenda as a demand for change-in this case, a clinical examination of mannitol. His term 'indications' referred to the fruits of the surveys, which did not replace clinical research, butunlike the initial mannitol study on fruit flies and mice—created a pool of patient data difficult to ignore. 


\section{Phases and tactics 3: framing—resistance}

CliniCrowd's efforts to address undone research involved tactics of framing and positioning - both of mannitol, and of themselves. The concept of framing has been heavily used by social movement researchers to describe how movements understand, interpret, and present - to themselves, and to others—what their organizations and movements 'mean', their values and goals. It is an important resource in mobilization work, whereby activists try to align their own frames with those of others whose cooperation or support they seek. They might, for instance, adopt frames of patriotism or motherhood, when seeking broad public support, or of resisting inequity, when seeking alliances with other aggrieved actors. But the frames adopted can vary, not only with the specific context and audience for which they are deployed, but also as an organization evolves over time (Snow et al. 1986, 2014; Benford and Snow 2000).

In fact, CliniCrowd's stance vis-à-vis the biomedical establishment has evolved over its short history. In the first interviews, the founders strongly criticized the pharmaceutical industry. For example, in the first interview with CEO Amir Sadeh, he described the decision to establish the company:

The goal is to create something that cannot be ignored and make available to the public what the pharmaceutical companies are trying to hide from us. Because they [such 'ignored' compounds] do not generate income, they do not make a profit, so it's better not to know about them at all. But now we're exposing them, showing their nakedness in public, telling them it's inexpensive and accessible. It treats the cause rather than the symptoms, and that's why it's the worst thing for the pharmaceutical companies to find a solution to Parkinson's disease. Ten million people, five billion dollars a year-as far as they're concerned, let's just treat the symptoms. It's cynical but that's the way it is.... [T] he benefit of the patients is not the paramount interest of the companies or the doctors, because they are waiting for the next seminar in the Seychelles, courtesy of one company or another. [interview December 3, 2017]

Sadeh's rhetoric framed CliniCrowd's founding as, at least partly, an act of resistance against the perverse negative incentivisation of the pharmaceutical industry, which—notably, for a businessman-he portrayed as cynical and corrupt.

Similarly, CliniCrowd's initial promotional materials, targeted to the wider public, repeatedly emphasized the pharmaceutical industry's reluctance to examine the effect of mannitol on Parkinson's patients. CliniCrowd portrayed their own efforts as a guerrilla campaign aimed at raising awareness and targeting gigantic, cynical corporations. Indeed, even in mid-2021, CliniCrowd's public website still exhorted: "Get more control over your life and your disease, including exploring natural approaches. You have the right to know about and explore nutriments and treatments that big pharma companies generally won't investigate" (URL: https://clinicrowd. info/what-we-do/ [accessed June 10, 2021]).

At the outset, CliniCrowd experienced significant difficulties in achieving trust and support from the medical establishment. From interviews we conducted with patients who began taking mannitol between 2016 and 2018, it appears that those 
who consulted their physicians encountered substantial resistance to mannitol. Physicians' objections included comments such as: "this is a home remedy" and, "you would be better off getting a blessing from a rabbi". At a neurologists' conference early in 2017, the CliniCrowd delegates were given only a few minutes to present, and most conference attendees ignored their talk. Such disdain recalls the boundarywork (see below) opposition directed at grassroots AIDS knowledge production over a generation ago (Indyk and Rier 1993, pp. 20-21), and illustrates, at least in mild form, Hess's (2016) observation that incumbents and elites might first attempt to ignore, and then to suppress or co-opt challengers (pp. 34-35). Recall Hess's words regarding cancer treatments, cited above, that those advocating for "less expensive... nutritional supplements... may even experience intellectual suppression...." (p. 28).

\section{Phases and tactics 4: re-framing and circumvention-(B) from resistance to complement}

However, as the fieldwork progressed, we noticed a shift in the attitude of CliniCrowd employees, in the company's discourse, and in media attitudes. At this point, we began to track the penetration of the term 'dietary supplement' into societal discourse. It appeared in interviews, fieldwork, content analysis, and in media appearances. Interviews made clear that the choice of the terms 'dietary supplements' and 'functional foods' reflected CliniCrowd's tactical decision to cease resisting pharmaceutical companies, in favour of creating a channel of influence and complementary action, by re-framing mannitol as a new substance in the food supplement market.

This is how CEO Sadeh described the change, in a follow-up interview:

We started out thinking we would call the venture Ampha, as opposed to Pharma. But the more we got into it, the more we realized that was not the point. Like Netflix doesn't mean all movie theatres are closed, and Airbnb hasn't replaced hotels, and Uber hasn't replaced taxis, so CliniCrowd won't replace the pharmaceutical companies. We fill a void and add something extra. If we started out by setting ourselves against the pharmaceutical companies, now we're not against them, we'll be in favour. We'll complement them. Let's shift the playing field. Instead of acting on the fiery and aggressive pharmaceutical playing field, let's move the field elsewhere....And as long as the whole world of medicine doesn't dance according to the interests of the pharmaceutical companies, we've done something great. [interview July 7, 2019]

It is interesting to examine the change in approach as reflected in interviews with Sadeh over time. This trend supports Hess's (2016, pp. 46-47) discussion of challengers shifting focus from that of replacing to complementing industrial actors. In this, it also echoes AIDS research, where activists initially profoundly hostile to the scientific and pharmaceutical establishments eventually chose to cooperate with them (Petersen et al. 2019; Harrington 1997; Maguire et al. 2004). Still, Sadeh's final sentence demonstrates that re-positioning themselves as complements rather than replacements did not necessarily mean that CliniCrowd fully renounced their critique of commercial influence. 
CliniCrowd's tactical shift is an example of boundary work (Gieryn 1983; Lamont and Molnar 2002) and boundary framing (Silver 1997; Benford and Snow 2000) in which, via re-framing, they withdrew from the risky drug arena, where they had challenged the pharmaceutical industry and the medical community, and relocated to a new niche in another arena, considered less important and therefore less threatening to powerful incumbents. CliniCrowd's actual operations did not change significantly. What did change was mainly how they chose to define and describe-to frame-their mannitol work.

Re-framing mannitol as a functional food proved a valuable manoeuvre, enabling CliniCrowd to disseminate the knowledge they had collected from patients without encountering significant objections. It appears that changing its orientation from resistance to creating an alternative, or complementary, channel of influence helped promote acceptance of mannitol among doctors and patients. Indeed, in the latter half of 2018, we noted an attitudinal change amongst physicians with whom we discussed mannitol. Three doctors interviewed for the study told us that, once they realized that this was a dietary supplement, they stopped objecting: "It is a dietary supplement. It may not help, but it's not harmful" [from an interview with Alona (pseudonym), a neurologist; April 17, 2019].

Actually, this change was presaged by interviews with patients. For example, 68-year-old Alexander [pseudonym] described how he informed his physician in 2018 of his intention to begin taking mannitol:

I went to my doctor and convinced him. I showed him it was not just something I had found, like a home remedy. I told him I was going to take it, and either he would jump on the bandwagon or I would look for a doctor who would agree to work with me the way I wanted. [interview Feb. 4, 2019]

Such pressure from patients who had been exposed-via forums, articles in the Israeli press, and the clinical survey site-to the possibility of a new treatment option, combined with the description of mannitol as a dietary supplement, softened attitudes of those physicians who formerly had objected. This, 'if you can't beat 'em, join 'em' approach arose also with AIDS, where patients' 'noncompliant' drug 'treatment holidays' led their physicians to explore the phenomenon more systematically, as 'structured treatment interruptions' (Rier and Indyk 2006b).

As Alona explained:

I think no doctor likes it when the patient comes and says, 'Listen, I've found a treatment.' Most of the time I have to make sure his feet are on the ground, and I must explain why, most probably, in his case it won't work. This was also my initial response to mannitol, complete resistance, not wanting them to take it....The attitude changes when there is already information and a mass of patients who have collated and documented its use in an orderly manner. Moreover, they didn't come and say this is a magic drug, but rather that it may help with some of the symptoms....I suggest to patients, especially at the beginning, that they should read about mannitol. I definitely don't exclude it, in fact quite the opposite. [emphasis added]. 
Overall, the company's tactical shift did promote acceptance of mannitol use among patients and physicians, and it helped launch clinical trials to examine its effect on Parkinson's patients.

To appreciate how the patients, themselves, experienced this, consider Menachem [pseudonym], 68, diagnosed some four years earlier. When asked about the experience of taking mannitol and participating in filling out the web questionnaire, he responded:

My participation in the experiment has turned my world around. I come to the doctor and update him, see? I, Menachem, taught the neurologist that there is such a thing as mannitol, and that I am taking part in an experiment with other patients. When I go to see him, he immediately stands up! 'Welcome', he says, 'tell me how you are getting on'. There is a sense that we are colleagues, and that I am doing something incredibly important. There is something in [mannitol] that helps, it's not a magical cure, or maybe I no longer suffer. But there is an improvement in my sleep, my sense of smell, and also my difficulty in movement. [interview Oct. 30, 2019]

Note the ease that Menachem describes in his relationship with the doctor, his feeling that he is an expert, his delight, and the agency he feels because of his participation. These are all so important to him that he mentions them even before his improved health, which he attributes to taking mannitol regularly.

\section{Discussion}

In this section, we summarize the special features of CliniCrowd and its work, suggest how our data contribute to the academic literature, and contemplate CliniCrowd's future.

CliniCrowd has demonstrated a new way of addressing undone science, by using crowd-sourced research to generate the public pressure and influence with which to attract scientists formally to test compounds with little profit potential. CliniCrowd represents an intersection of scientific knowledge, technologies, practices, shifting socio-cultural definitions of the patient role, mobilization of patients, commercial market forces, government regulation, and the work of social entrepreneurs who helped define and achieve project aims. Fundamentally, it is also the product of a sustained process of diffusion and de-centralization of expertise (Eyal 2019).

Our data extend the literature on undone science by illuminating a less-studied corner. Hess's (2016) mapping of undone science is comprehensive, sophisticated, and culturally-, politically-, and sociologically-grounded. It presciently accounts for the possibility of numerous aspects of the CliniCrowd case, such as entrepreneurial efforts, and even notes the obstacles faced by advocates of non-pharmaceutical disease management. Yet, while his typologies form the blueprint for another generation's worth of empirical studies of undone science in all its forms, very few empirical undone science studies have yet been performed beyond the area of environmental issues, and virtually none at all on orphan drugs; a key contribution of our own study is to address this gap. We focus on health, rather than the environment. 
We also identify orphan drugs as an important form of undone science, quite fertile ground both for future citizen science and sociological research thereon. This orphan drug problem, of course, prevents potentially valuable treatments from reaching patients.

The present study also adds empirical flesh to the massive framework Hess furnished, finding support-as noted throughout this paper-for several of his specific observations. Indeed, his model helps us see how CliniCrowd's innovation operated on at least two levels. First, its raison d'être was originally testing mannitol, a particular product, or technology (treatment). Yet their innovation went deeper. For CliniCrowd, itself, developed, and developed into, a process or 'technology' for identifying and testing 'natural' orphan treatment alternatives. They assembled and adapted existing tools and techniques from earlier examples of evidence-based citizen-science, including such 'proto-tools' (Callon and Rabeharisoa 2003) as surveys (Brown and Mikkelsen 1990; Callon and Rabeharisoa 2003; Akrich et al. 2014) and digital crowd-sourcing platforms for self-surveillance (Kempner and Bailey 2019), including PLM's platform (Wicks 2018). However, CliniCrowd eschewed the typical non-profit route, investing their own resources and applying an entrepreneurial, tactical style of operations to: identify candidate 'orphan' substances; test them; use those tests to stimulate subsequent advanced testing; and then-by re-framing the substances as nutritional supplements-promote their use as non-pharmaceutical treatments. CliniCrowd is closest to the "product-oriented" type of "alternative industrial movement" (Hess 2016, pp. 21, 43, 45), innovating around both product and process.

Indeed, despite some of their earlier 'resistance' rhetoric, CliniCrowd embraced primarily a pragmatic entrepreneurial-rather than activist-approach. While their functions situate them within the field of evidence-based activism (Akrich et al. 2014; Rabeharisoa et al. 2014b), CliniCrowd's leadership did not seem to regard themselves as activists. Significantly, they never, ever mentioned the term during interviews. Instead, they portrayed themselves as pragmatic problem-solvers, interested in circumventing obstacles and inefficiency.

This raises the question: can there be activism without activists? Whether we consider CliniCrowd's founders to be activists depends partly on the relative weights we accord motives, methods, and results. Perhaps, pace Callon and Rabeharisoa's suggestion (2003, p. 203), grassroots knowledge production need not imply identity construction? More prosaically, what shall we call them? 'Citizen-scientists' at least avoids the assumption of socio-political orientation, but it is unlikely that they saw themselves as scientists, either. Future studies of entrepreneurial citizen-science can probe questions of identity, framing, and nomenclature. For now, note that, while the principals of CliniCrowd saw themselves as pragmatic entrepreneurs, a central aspect of their work has depended on crowd-sourcing; these patients likely included many with some treatment-activist mentality, in addition to their pragmatic wish for better treatment.

CliniCrowd is interesting for several reasons, which help expand our conceptualizations of patient treatment activism and citizen-science more generally (and which two literatures our paper-in a separate contribution-links with that of undone science). 
First is the founders' slightly incongruous position as 'establishment rebels'. CliniCrowd-originally framed as bottom-up resistance against the profitoriented pharmaceutical industry — was created by elite members of the Israeli establishment, those rarely ranked at the bottom of any social metric. While activists for conditions such as AIDS were often highly educated (e.g., Epstein 1996, pp. 229-230; Burkett 1995, pp. 320-321), many others held marginal status due to their being female or homosexual. Activists around toxic-exposed communities were often working-class (e.g., Cable and Cable 1995; Brown and Mikkelsen 1990). Conversely, CliniCrowd's founders possessed immense social, cultural, financial, and symbolic capital within Israel's comparatively militarized society (Levy 2020). In Israel, the defence and high-tech start-up elites are often considered amongst society's brightest and most innovative, trained from youth to assume responsibility, think creatively, collaborate, and take risk (Honig et al. 2006; Baram and Ben-Israel 2019; Swed and Butler 2015; Katz and Bohbot 2017; Gewirtz 2016). This demonstrates Hess's (2016, pp. 18, 26, 53) observation that challenging "counterpublics" need not, necessarily, occupy positions of structural inequality and marginality, as traditional social movement theories tend to expect. Rather, they may include intellectuals, scientists, professionals, and entrepreneurs, as occurred in elite actors' promotion of Buddhism, for example (Kucinskas 2019).

Second, unlike many other patient activists, their pragmatic, entrepreneurial mentality led to their tactical decision to register as a corporation, rather than a non-profit.

Third, the same mentality led them to side-step challenges by re-framing mannitol as a food supplement, not a drug. This one decision did two things for CliniCrowd. It let them avoid the slow, expensive pharmaceutical approval process. It also meant that they were no longer positioned against conventional medical authority; this, in turn, facilitated consensus. This creative piece of boundary-work may be a fruitful approach for promoting other such orphan drugs. Indeed, similar tactics have been employed by new religious/spiritual movements seeking to grow without direct, costly challenges to established institutions (Kucinskas 2014; Pagis et al. 2018).

Fourth, this tactical shift in their self-presentation apparently reflected a broader evolution, over a fairly short time-frame, in their self-perception, from viewing themselves as resistors of the biomedical/pharmaceutical establishment to regarding themselves as complements to it.

Fifth, much of their contribution lies, not in conducting trials of promising treatments, but in their directed, 'surgical' efforts at identifying likely candidates in the first place, and then using their crowd-sourced data to press physicians and credentialed scientists to conduct more formal studies, thus addressing undone science (while also reprising the role of AIDS treatment activists a generation ago [e.g., Epstein 1996; Harrington 1997]).

Sixth, unlike the relative youth of many treatment activists, such as those for AIDS, CliniCrowd's founders are elderly. This is unsurprising, considering Parkinson's demographics. However, as we suggest below, this could pose certain organisational problems over time. 
Seventh, similar to French muscular dystrophy activism (Callon and Rabeharisoa 2003) and European childbirth activism (Akrich et al. 2014) - though unlike British breast cancer activism (Frickel et al. 2010, pp. 458-460)-CliniCrowd's treatment entrepreneurship has paralleled Parkinson's patients' citizen-science efforts, through PLM, to expand Parkinson's activism beyond the traditional efforts to raise awareness and research funds.

\section{Looking ahead}

Thanks largely to CliniCrowd, Parkinson's patients and physicians are increasingly aware of mannitol, a compound of possible clinical value to them. Still, the ultimate utility of crowd-sourced research is controversial. While observers such as Bain (2008) see enormous potential, others criticize it as yielding subjective and anecdotal data (Gorski 2012). As explained above, we have bracketed out the question of mannitol's benefit for Parkinson's patients. But CliniCrowd's future surely depends, at least in part, on what happens with mannitol.

Several trajectories are possible for CliniCrowd. For example: the company has already begun registering patients to evaluate cherries to help manage gout, and cinnamon extract to prevent cognitive decline in Alzheimer's patients (https://clini crowd.info/; accessed June 14, 2021). Such substances are, like mannitol, orphan drugs-hence, candidates for framing as nutritional substitutes. These offer a niche for CliniCrowd; they could begin marketing and distributing natural substances such as mannitol as nutritional supplements, even issuing some sort of 'seal of approval', based on their crowd-sourced data; see Hess (2016, pp. 45-47) on certification. Moreover, our follow-up interviews revealed that CliniCrowd has begun developing mobile applications that can monitor Parkinson's symptoms, such as tremor and voice quality, to add a quantitative dimension to their monthly survey.

Perhaps they may eventually outsource some of their functions. While our informants have explained that CliniCrowd's online platform was custom-built for their needs, they might someday decide to refer their recruits to the existing PLM infrastructure for operating their study. This could free them to focus on their particular mission of identifying promising natural substances to test.

Whatever path they select: will renewed leadership and funding sustain CliniCrowd long-term, or is it simply a project of the original, aging (and ailing) leadership? This question would be even more salient should mannitol's clinical utility not be supported by the research arising from their efforts. Perhaps, to fund continued operations, they will follow PLM, and sell access to aggregated, de-identified data.

CliniCrowd's founders might even wind down after mannitol has been properly tested, having accomplished their original mission. Then, too, their preference to be small, nimble, and mission-oriented could leave them without the organizational tools and culture to enable smooth, stable transition to a new generation of leadership. Yet 
their approach does mesh well with patient activism in the current digital era, in which fluidity and time- and function-limited engagement mark the new 'connective action' conducted via social media, and independent of formal, hierarchical organizations and ideologies (Vicari and Cappai 2016; McElhiney et al. 2020, p. 11). Perhaps addressing undone science about natural compounds will involve, in future, targeted efforts of temporary coalitions of patients motivated only to shepherd 'their' candidate treatment through testing, and then disbanding.

Alternatively, turning away from their current 'disease constituency' mobilisation framework (Epstein 2016), CliniCrowd might broaden their treatment activism focus by seeking alliances beyond the world of Parkinson's. One likely alliance candidate might be activists for rare diseases and/or those requiring orphan drugs (Pinto et al. 2018; McGowan et al. 2017, p. 503), for whom CliniCrowd's crowd-sourced tactics for addressing undone science could prove especially valuable (Rabeharisoa et al. 2014a).

\section{Future research}

The present research suggests numerous areas for future studies. One such would be interviewing CliniCrowd patient-participants, to compare their experience with that of platforms such as PLM. The present authors plan to publish such a paper on this dataset.

A full exploration of CliniCrowd's significance for social movements research is beyond the scope of the present paper, which focuses mainly on undone science. Still, future studies could contribute to the social movements literature by identifying and analysing similar efforts, from a social movements perspective. One particular challenge would be quantitatively to isolate the stages at which a critical mass — of data, of resources, of'buzz' - develops to trigger given key events in the acceptance of citizenscientists' goals and strategies. Such work could expand our knowledge of collective self-experimentation (Kempner and Bailey 2019), by focusing on what it takes to trigger other, more powerful actors to embrace and extend the work.

Future research could explore other such examples of entrepreneurial citizen-science as tools for addressing different types of undone science, in different fields, healthrelated or not. Research on "the organizational forms of counterpublic knowledge is still very much in its infancy..." (Hess 2016, p. 159). In its focus on the interesting Israeli context, moreover, our paper marks one small response to Hess's (2016, p. 33) observation that "[d]eveloping a global perspective on undone science... remains a challenge for future research." As additional, more varied studies accumulate, scholars 
can refine their taxonomies by isolating which conditions and contexts are most conducive for which types of activity. Beyond the specific sub-fields of undone science, treatment activism, and citizen-science, entrepreneurial activism bears interest for the wider fields of sociology and anthropology of medicine, STS, and social movement studies.

\section{Conclusion}

In the Discussion, we suggested how our data advance the academic literature. Here, we shift our gaze to the applied fields of citizen-science and treatment activism. We highlight a model, emerging from our data, for a new, entrepreneurial orientation, and a new set of techniques, for future efforts to do undone science.

Figure 1 depicts this model's essentials. Identify untested treatments (such as natural compounds or other types of orphan drugs) ripe for crowd-sourced testing. Perform these tests. Then, leverage them to attract more formal studies. Next, use these formal studies, along with the crowd-sourced 'alternative' research, as well as a critical mass of motivated patients, to generate public pressure for further testing and use. The model also includes a preference to operate more as missile boat than battleship, and to avoid direct confrontation with powerful established actors by exploiting opportunities to complement rather than resist them.

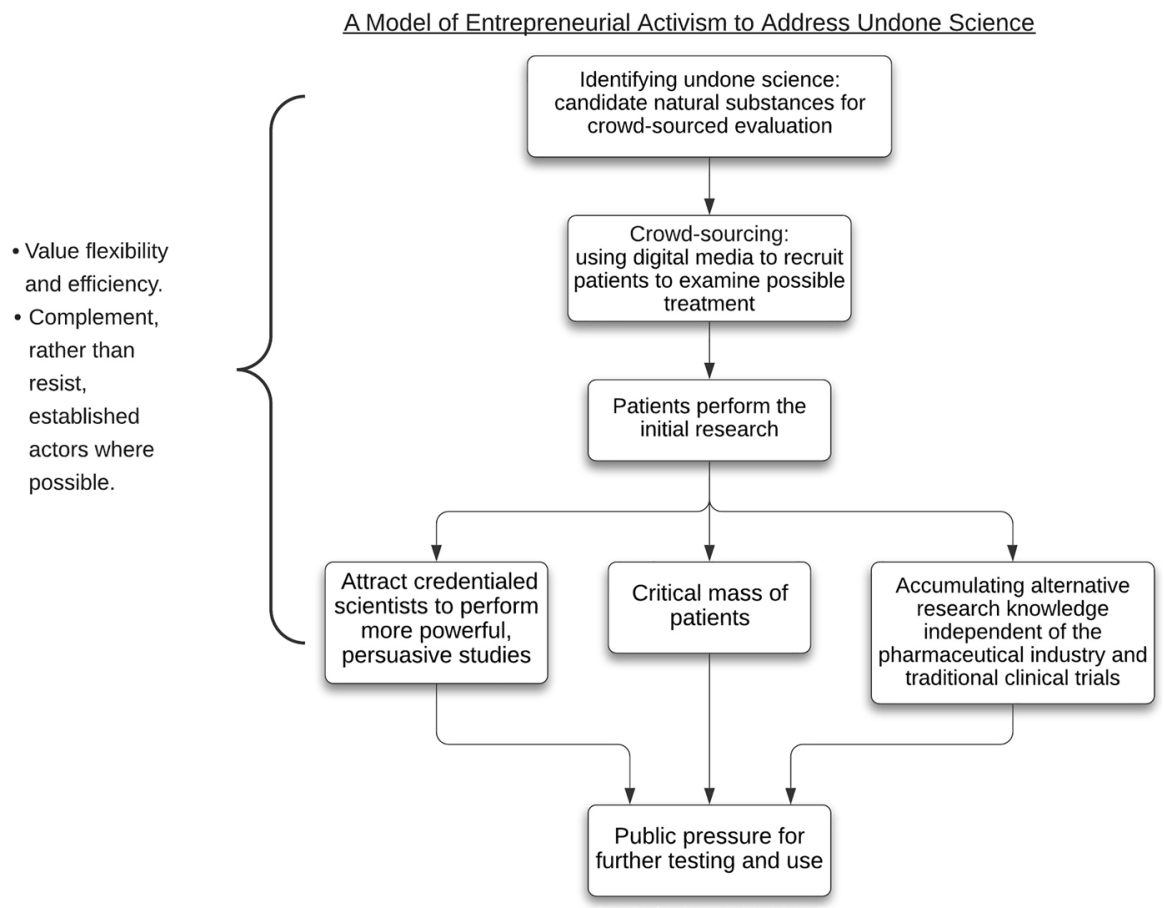

Fig. 1 A model of entrepreneurial activism to address undone science 
Numerous diseases, such as Alzheimer's, diabetes, multiple sclerosis, and cancers, could benefit from such an approach. There exist countless botanicals and other natural compounds that are effectively orphan drugs, hence appropriate candidates for this entrepreneurial, crowd-sourced approach to treatment activism. Alternative healing techniques such as massage, which lack significant financial incentives to invest in testing, might be another category. But the model could conceivably apply beyond the field of treatments altogether. For example, modified versions of the model might be applied to techniques or devices in the environmental field.

CliniCrowd's founders were wealthy and supremely well-connected. Are these undoubted advantages critical? Is this merely a 'boutique' model, irrelevant to patient groups possessing more modest socio-economic and cultural capital? Not necessarily: they could use crowd-sourced fundraising platforms such as GoFundMe. Also, PLM's existing research platform is available to patient groups free of charge. Various patient groups might choose to adopt the model in full, or only in part.

Neither does adoption necessarily require a staff stocked with former generals and commandos to supply creative solutions to obstacles. Certainly, many entrepreneurs, coming from high-tech or elsewhere, can supply such an approach to achieving their goals. Nor need leaders possess military or business backgrounds at all. Already half a century ago, Alinsky ([1971]1989) codified a 'civilian' activist version of a tactical, thinking-out-of-the-box approach, one developed from experiences in areas such as labour organising and civil rights activism. U.S. AIDS activists of the 1980s and 1990s employed various out-of-the-box techniques, from ACT-UP's aggressive street theatre (Burkett 1995) to its spun-off Treatment Action Group (TAG) (Crewe 2018; McElhiney et al. 2020). A prime example of the shift, detailed above, from working against the system to working within it, TAG learned enough about the process of pharmaceutical development eventually to earn a 'place at the table', through which they influenced regulatory priorities and procedures for developing and approving new treatments (Epstein 1996) to address undone science. See Maguire, et al. (2004) for a description of a similar evolution in Canada.

For now, our study of CliniCrowd demonstrates that its citizen-science builds on earlier treatment activisms to combine patients, science, technology, and capital in new ways. They have addressed commercial market-created barriers to performing undone science by working from within the market, employing an entrepreneurial spirit and tactics, rather than a politicised orientation relying on such methods as protests, petitions, and hearings. They have extended the 'do-it-yourself' approach pioneered by AIDS activists (Epstein 1996), and later adopted by ALS, Parkinson's, and diabetes patients (Wicks 2018), and by patients and other citizen-scientists engaged even in genomics research (McGowan et al. 2017).

It will be interesting to discover what alternative pathways future entrepreneurial citizen-science treatment activists construct to perform research that, in the face of market forces and other interests, the establishment fails to conduct.

Acknowledgements The authors confirm that this manuscript is comprised of original material that is not under review elsewhere, and that the study on which this research is based has been subject to appropriate ethical review. We also confirm that we have no competing interests, neither intellectual nor 
financial, in the research detailed in the manuscript. We would like to thank our good friends, colleagues, and students Michal Pagis, Shira Klimor- Maman, Omri Grinberg, and Nadav Koren for their careful reading and constructive comments on preliminary drafts of this manuscript. Special thanks to the four anonymous reviewers of BioSocieties for their substantial and constructive comments on the advanced versions of this article. This paper is dedicated to the memory of our fathers, Moshe Guzmen and Stanley Rier and to the families dealing with Parkinson's disease.

\section{Declarations}

Conflict of interest On behalf of all authors, the corresponding author states that there is no conflict of interest.

\section{References}

Acumen Research and Consulting. 2021. Frequently asked questions. https://www.acumenresearcha ndconsulting.com/parkinsons-disease-market. Accessed 9 Feb 2021.

Agency for Healthcare Research and Quality. 2017. PatientsLikeMe. March. https://www.ahrq.gov/worki ngforquality/priorities-in-action/patientslikeme.html Accessed 18 Feb 2021.

Akrich, M., M. Leane, C. Roberts, and J.A. Nunes. 2014. Practising childbirth activism: A politics of evidence. BioSocieties 9 (2): 129-152.

Alinsky, S.D. [1971]1989. Rules for radicals: A practical primer for realistic radicals. Kindle ed. New York: Vintage.

Allen, B.L., Y. Ferrier, and A.K. Cohen. 2017. Through a maze of studies: Health questions and "undone science" in a French industrial region. Environmental Sociology 3 (2): 134-144.

Arancibia, F., and R. Motta. 2019. Undone science and counter-expertise: Fighting for justice in an Argentine community contaminated by pesticides. Science as Culture 28 (3): 277-302.

Arno, P.F., and K.F. Feiden. 1992. Against the odds: The story of AIDS drug development, politics, \& profits. New York: HarperCollins.

Bain, W. 2008. Truly personalised medicine: Self-experimentation in medical discovery. Medical Hypothesis 70 (4): 714-718.

Baram, G., and I. Ben-Israel. 2019. The academic reserve: Israel's fast track to high-tech success. Israel Studies Review 34 (2): 75-91.

Benford, R.D., and D.A. Snow. 2000. Framing processes and social movements: An overview and assessment. Annual Review of Sociology 26 (1): 611-639.

Bilu, Y. 2010. The saints' impresarios: Dreamers, healers, and holy men in Israel's urban periphery. Boston: Academic Studies Press.

Boston Women's Health Book Collective (BWHBC). 1970. Women and their bodies. Boston: New England Free Press. https://www.ourbodiesourselves.org/cms/assets/uploads/2014/04/Women-andTheir-Bodies-1970.pdf. Accessed 12 Feb 2021.

Braun, V., and V. Clarke. 2006. Using thematic analysis in psychology. Qualitative Research in Psychology 3 (2): 77-101.

Brown, P. 1992. Popular epidemiology and toxic waste contamination: Lay and professional ways of knowing. Journal of Health and Social Behavior 33 (3): 267-281.

Brown, P., and E.J. Mikkelsen. 1990. No safe place: Toxic waste, leukemia, and community action. Berkeley: University of California.

Burkett, E. 1995. The gravest show on Earth: American in the age of AIDS. Boston: Houghton Mifflin.

Cable, S., and C. Cable. 1995. Environmental problems, grassroots solutions: The politics of grassroots environmental conflict. New York: St. Martin's.

Callon, M., and V. Rabeharisoa. 2003. Research 'in the wild' and the shaping of new social identities. Technology in Society 25 (2): 193-204.

Cimons, M. 1989. Minorities, drug users targets of AIDS research. Los Angeles Times, 6 October, p. 41.

Cleary, T. 2012. Undone science and blind spots in medical treatment research. Social Medicine 6 (4): 234-239. 
Conrad, P., J. Bandini, and A. Vasquez. 2016. Illness and the Internet: From private to public experience. Health 20 (1): 22-32.

Cousins, N. 1976. Anatomy of an illness (as perceived by the patient). New England Journal of Medicine 295 (26): $1458-1463$.

Crewe, T. 2018. Here was a plague. London Review of Books 40 (18): 1-25.

Epstein, S. 1991. Democratic science? AIDS activism and the contested construction of knowledge. Socialist Review 21 (2): 35-64.

Epstein, S. 1996. Impure science: AIDS, activism, and the politics of knowledge. Berkeley: University of California.

Epstein, S. 2016. The politics of health mobilization in the United States: The promise and pitfalls of "disease constituencies." Social Science \& Medicine 165: 246-254.

Eyal, G. 2019. The crisis of expertise. Kindle. Cambridge: Polity.

Frickel, S. 2014. Not here and everywhere: The non-production of scientific knowledge. In Routledge handbook of science, technology, and society, ed. D.L. Kleinman and K. Moore, Kindle ed., 263276. London: Routledge.

Frickel, S., S. Gibbon, J. Howard, J. Kempner, G. Ottinger, and D.J. Hess. 2010. Undone science: Charting social movement and civil society challenges to research agenda setting. Science, Technology \& Human Values 35 (4): 444-473.

Gewirtz, J. 2016. Israel's edge. Jerusalem: Gefen.

Gieryn, T.F. 1978. Problem retention and problem change in science. Sociological Inquiry 48 (34): 96-115.

Gieryn, T.F. 1983. Boundary-work and the demarcation of science from non-science: Strains and interests in professional ideologies of scientists. American Journal of Sociology 48 (6): 781-795.

Goldstein, D.M. 2017. Fukushima in Brazil: Undone science, technophilia, epistemic murk. Culture, Theory and Critique 58 (4): 391-412.

Gorski, D. 2012. The perils and pitfalls of "patient-driven" clinical research. Science-based Medicine [blog], 30 July, https://sciencebasedmedicine.org/the-perils-of-patient-driven-clinical-research/. Accessed $11 \mathrm{Feb} 2021$.

Gross, M., and Linsey McGoey, eds. 2015. Routledge international handbook of ignorance studies. Kindle. London: Routledge.

Gusfield, J.R. 1981. The culture of public problems: Drinking-driving and the symbolic order. Chicago: University of Chicago.

Hagstrom, W.O. 1965. The scientific community. Carbondale: Southern Illinois University.

Hanssmann, C. 2020. Epidemiological rage: Population, biography, and state responsibility in transhealth activism. Social Science \& Medicine 247: 112808.

Harrington, M. 1997. Some transitions in the history of AIDS treatment activism. In Acting on AIDS: Sex, drugs \& politics, ed. J. Oppenheimer and H. Reckitt, 273-286. New York: Serpent's Tail.

Hess, D.J. 1998. The problem of undone science: Values, interests, and the selection of research programs. Presented at the annual meeting of the Society for Social Studies of Science (4S), October, Halifax, NS.

Hess, D.J. 2009. The potentials and limitations of civil society research: Getting undone science done. Sociological Inquiry 79 (3): 306-327.

Hess, D.J. 2015. Undone science and social movements. In The Routledge international handbook of ignorance studies, ed. Matthias Gross and Linsey McGoey, Kindle ed., 141-154. New York: Routledge.

Hess, D.J. 2016. Undone science: Social movements, mobilized publics, and industrial transitions. Kindle. Cambridge: MIT Press.

Hilgartner, S., and C.L. Bosk. 1988. The rise and fall of social problems: A public arenas model. American Journal of Sociology 94 (1): 53-78.

Honig, B., M. Lerner, and Y. Raban. 2006. Social capital and the linkages of high-tech companies to the military defense system: Is there a signaling mechanism? Small Business Economics 27 (4-5): 419-437.

Indyk, D., and D.A. Rier. 1993. Grassroots AIDS knowledge: Implications for the boundaries of science and collective action. Knowledge: Creation, Diffusion, Utilization 15 (1): 3-43.

James, J.J. 1989. AIDS treatment news: Issues 1 through 75. Berkeley: Celestial Arts.

Katz, Y., and A. Bohbot. 2017. The weapon wizards: How Israel became a high-tech military superpower. New York: St. Martin's. 
Kempner, J., and J. Bailey. 2019. Collective self-experimentation in patient-led research: How online health communities foster innovation. Social Science \& Medicine 238: article \#112366, 1-8.

Kucinskas, J. 2014. The unobtrusive tactics of religious movements. Sociology of Religion 75 (4): $537-550$.

Kucinskas, J. 2019. The mindful elite: Mobilizing from the inside out. Kindle. New York: Oxford University.

Lamont, M., and V. Molnar. 2002. The study of boundaries across the social sciences. Annual Review of Sociology 28: 167-195.

Levy, Y. 2020. Israel: A politically monitored military in a militarized society. In Oxford research encyclopedia of politics, ed. W.R. Thompson. Oxford: Oxford University Press.

Lieblich, A., R. Tuval-Mashiach, and T. Zilber. 1998. Narrative research: Reading, analysis, and interpretation, vol. 47. Thousand Oaks: SAGE.

Lowe, K. 2020. Undone science, funding, and positionality in transportation research. Transport Reviews. https://doi.org/10.1080/01441647.2020.1829742.

Lupton, D. 2013. The digitally engaged patient: Self-monitoring and self-care in the digital health era. Social Theory and Health 11 (3): 256-270.

Lupton, D. 2017. Self-tracking, health and medicine [editorial]. Health Sociology Review 26 (1): 1-5.

Maguire, S., C. Hardy, and T.B. Lawrence. 2004. Institutional entrepreneurship in emerging fields: HIV/ AIDS treatment advocacy in Canada. Academy of Management Journal 47 (5): 657-679.

Andrews, M., C. Squire, and M. Tamboukou, eds. 2013. Doing narrative research. Thousand Oaks: SAGE.

McElhiney, M.C., J.G. Rabkin, M.R. Finkel, T. Horn, and M. Harrington. 2020. Portraits of activism: ACT-UP in retrospect. Journal of Cultural Analysis and Social Change 5 (1): 04.

McGowan, M.L., S. Choudhury, E.T. Juengst, M. Lambrix, R.A. Settersten, and J.R. Fishman. 2017. 'Let's pull these technologies out of the ivory tower': The politics, ethos, and ironies of participantdriven genomic research. BioSocieties 12 (4): 494-519.

Merigan, T.C. 1990. You can teach an old dog new tricks: How AIDS trials are pioneering new strategies. New England Journal of Medicine 323 (19): 1341-1343.

Mikami, K. 2017. Orphans in the market: The history of orphan drug policy. Social History of Medicine 32 (3): 609-630.

Miles, M.B., and M.A. Huberman. 1994. Qualitative data analysis: An expanded sourcebook. Thousand Oaks: SAGE.

Norsigian, J., V. Diskin, P. Doress-Worters, J. Pincus, W. Sanford, and N. Swenson. 1999. The Boston women's health book collective and our bodies, ourselves: A brief history and reflection. Journal of the American Medical Women's Association 54 (Winter): 35-36.

Orphanet. 2019. What is an orphan drug? https://www.orpha.net/consor/cgi-bin/Education_AboutOrpha nDrugs.php?lng=EN. Accessed 8 Feb 2021.

Ottinger, G. 2017. Crowdsourcing undone science. Engaging Science, Technology, and Society 3: 560-574.

Pagis, M., W. Cadge, and O. Tal. 2018. Translating spirituality: Universalism and particularism in the diffusion of spiritual care from the United States to Israel. Sociological Forum 33 (3): 596-618.

Panikkar, B. 2020. 'Litigation is our last resort': Addressing uncertainty, undone science, and bias in court to assert indigenous rights. Nature and Culture 15 (2): 173-198.

Parsons, T. 1951. The social system. Glencoe: Free Press.

PatientsLikeMe. 2020. How does PatientsLikeMe make money? December. https://support.patientsli keme.com/hc/en-us/articles/201245750-How-does-PatientsLikeMe-make-money-. Accessed 12 Feb 2021.

Petersen, A., C. MacGregor, and M. Munsie. 2015. Stem cell miracles or Russian roulette? Patients' use of digital media to campaign for access to clinically unproven treatments. Health, Risk \& Society 17 (7/8): 592-604.

Petersen, A., A.C. Schermuly, and A. Anderson. 2019. The shifting politics of patient activism: From biosociality to bio-digital citizenship. Health 23 (4): 478-494.

Petracci, M., P.K.N. Schwarz, V.I.M. Sánchez Antelo, and A.M. Mendes Diz. 2017. Doctor-patient relationships amid changes in contemporary society: A view from the health communication field. Health Sociology Review 26 (3): 266-279.

Pinto, D., D. Martin, and R. Chenhall. 2018. Chasing cures: Rewards and risks for rare disease patient organisations involved in research. BioSocieties 13 (1): 123-147. 
Piras, E.M., and F. Miele. 2017. Clinical self-tracking and monitoring technologies: Negotiations in the ICT-mediated patient-provider relationship. Health Sociology Review 26 (1): 38-53.

Rabeharisoa, V., M. Callon, A.M. Filipe, J.A. Nunes, F. Paterson, and F. Vegnaud. 2014a. From 'politics of numbers' to 'politics of singularisation': Patients' activism and engagement in research on rare diseases in France and Portugal. BioSocieties 9 (2): 194-217.

Rabeharisoa, V., T. Moreira, and M. Akrich. 2014b. Evidence-based activism: Patients', users' and activists' groups in knowledge society. BioSocieties 9 (2): 111-128.

Ragin, C.C., and H.S. Becker, eds. 1992. What is a case? Exploring the foundations of social inquiry. Cambridge: Cambridge University Press.

Rier, D.A., and D. Indyk. 2006a. The rationale of interorganizational linkages to connect multiple sites of expertise, knowledge production, and knowledge transfer: An example from HIV/AIDS services for the inner city. Social Work in Health Care 42 (3): 8-27.

Rier, D.A., and D. Indyk. 2006b. Flexible rigidity: Supporting AIDS treatment adherence in a rapidlychanging treatment environment. Social Work in Health Care 42 (3): 133-150.

Shaltiel-Karyo, R., M. Frenkel-Pinter, E. Rockenstein, C. Patrick, M. Levy-Sakin, A. Schiller, N. EgozMatia, E. Masliah, D. Segal, and E. Gazit. 2013. A blood-brain barrier (BBB) disrupter is also a potent $\alpha$-synuclein ( $\alpha$-syn) aggregation inhibitor: A novel dual mechanism of mannitol for the treatment of Parkinson disease (PD). Journal of Biological Chemistry 288 (24): 17579-17588.

Silver, I. 1997. Constructing "social change" through philanthropy: Boundary framing and the articulation of vocabularies of motives for social movement participation. Sociological Inquiry 67 (4): 488-503.

Snow, D., R. Benford, H. McCammon, L. Hewitt, and S. Fitzgerald. 2014. The emergence, development, and future of the framing perspective: $25+$ years since "frame alignment." Mobilization: an International Quarterly 19 (1): 23-46.

Snow, D.A., E.B. Rochford Jr., S.K. Worden, and R.D. Benford. 1986. Frame alignment processes, micromobilization, and movement participation. American Sociological Review 51 (4): 464-481.

Swan, M. 2012. Crowdsourced health research studies: An important emerging complement to clinical trials in the public health research ecosystem. Journal of Medical Internet Research 14 (2): e46.

Swed, O., and J.S. Butler. 2015. Military capital in the Israeli hi-tech industry. Armed Forces \& Society 41 (1): 123-141.

Vicari, S., and F. Cappai. 2016. Health activism and the logic of connective action: A case study of rare disease patient organisations. Information, Communication \& Society 19 (11): 1653-1671.

Warren, J. 2015. When undone science stifles innovation: The case of the Tasmanian devil cancer. Prometheus 33 (3): 257-276.

Wazny, K. 2018. Applications of crowdsourcing in health: An overview. Journal of Global Health 8 (1): $1-20$.

Weisse, A.B. 2012. Self-experimentation and its role in medical research. Texas Heart Institute Journal 39 (1): 51-54.

Wicks, P. 2018. Patient, study thyself. BMC Medicine 16: 217.

Wicks, P., M. Massagli, J. Frost, H. Macedo, K. Felzer, and J. Heywood. 2008. A patient-led trial of lithium in ALS using the Internet. Amyotrophic Lateral Sclerosis 9 (Suppl 1): 59.

Woodhouse, E., D. Hess, S. Breyman, and B. Martin. 2002. Science studies and activism: Possibilities and problems for reconstructivist agendas. Social Studies of Science 32 (2): 297-319.

Yin, K.R. 2018. Case study research and applications: Design and method, 6th ed. Thousand Oaks: Sage Publications.

Ziman, J.M. 1987. The problem of 'problem choice'. Minerva 25 (1-2): 92-106.

Zuckerman, H. 1978. Theory choice and problem choice in science. Sociological Inquiry 48 (34): 65-95.

Publisher's Note Springer Nature remains neutral with regard to jurisdictional claims in published maps and institutional affiliations.

Shlomo Guzmen-Carmeli is Lecturer in the Sociology and Anthropology Department of Bar-Ilan University. His research fields of interest are: anthropology of medical research; the anthropology of knowledge and learning; text and society; anthropology and sociology of religion; and ritual healing. 
David A. Rier is Senior Lecturer in the Sociology and Anthropology Department of Bar-Ilan University. His research encompasses medical sociology, sociology of science and knowledge, and public health, with a long-standing focus on varieties of expertise. Currently, he chairs the Israeli Sociological Society's section on Knowledge, Science, and Technology. 